\title{
Antibacterial Activity and Phytochemical Screening of Garcinia pedunculata Roxb. ex Buch. - Ham. fruit extract by HPLC-ESI-MS
}

\author{
Zoliansanga* (D) and R. Lalfakzuala \\ Department of Botany, Microbiology Laboratory, Mizoram University, Aizawl - 796 004, Mizoram, India.
}

\begin{abstract}
Disc and well diffusion methods were used to test the antibacterial activity of methanol extract and ethanol extract of the selected ethnomedicinal plant viz. Garcinia pedunculata Roxb. ex Buch.-Ham. Both the methanol extract and ethanol extract were subjected to antibacterial activity assay against the six clinical isolates. Antibiotic sensitivity test of the test bacteria against standard antibiotics were also determined. All the bacterial pathogens (Staphylococcus aureus, Enterococcus faecalis, Enterobacter cloacae, Escherichia coli, Pseudomonas aeruginosa and Klebsiella pneumoniae) were exposed to the plant extract in triplicates. The investigation revealed the potency of $G$. pedunculata extract as an effective antibacterial agent against both Gram-positive bacteria (GPB) and Gram-negative bacteria (GNB). G. pedunculata are evaluated to be bactericidal against the tested bacteria. The antibacterial activity may be due to an individual compound or synergistic effect of more than one compound present in the medicinal plant extract. The minimum inhibitory concentrations (MIC) and minimum bactericidal concentrations (MBC) of the plant extracts were also investigated by using the broth microdilution method. HPLC-MS of the methanol extract of $G$. pedunculata fruit revealed the presence of Hydroxy Citric Acid Lactone (MW-190), Garcinone-E (MW-464), $\alpha-$ Mangostin (MW-410), $\beta$-Mangostin (MW424), and $\mathrm{Y}$-Mangostin (MW-396).
\end{abstract}

Keywords: Garcinia pedunculata, phytochemicals, antimicrobial activity, Mueller Hinton Agar, Resazurin, Retention time

*Correspondence: zolian15@yahoo.com

(Received: August 11, 2021; accepted: September 27, 2021)

Citation: Zoliansanga, Lalfakzuala R. Antibacterial Activity and Phytochemical Screening of Garcinia pedunculata Roxb. ex Buch. - Ham. fruit extract by HPLC-ESI-MS. J Pure Appl Microbiol. 2021;15(4):2183-2194. doi: 10.22207/JPAM.15.4.42

(C) The Author(s) 2021. Open Access. This article is distributed under the terms of the Creative Commons Attribution 4.0 International License which permits unrestricted use, sharing, distribution, and reproduction in any medium, provided you give appropriate credit to the original author(s) and the source, provide a link to the Creative Commons license, and indicate if changes were made. 


\section{INTRODUCTION}

Garcinia pedunculata Roxb. ex Buch.Ham. is well recognized as medicinal plants amongst the tribals of North Eastern States of India. G. pedunculata fruit are used in the treatment of stomachache, diarrhea and urinary tract disorder. ${ }^{1}$ Medicinal plants contain diverse array of secondary metabolites which have significant antioxidant and antibacterial properties.

There are more than 200 species of Garcinia (family: Clusiaceae), distributed in tropical regions of the world, mainly in Asia, Africa and Polynesia. They are medium size evergreen trees. There are around 35 species in India, many of which are endemic, with significant economic importance and great medicinal value. ${ }^{2}$ In India, different species of Garcinia are found in Gujarat, West Bengal, Jaintia Hills, Khasi Hills, Assam, Konkan region of Maharashtra, Goa, Karnataka and Kerala coastal areas. It grows widely in the semi-wild state in the evergreen forests. G.kydia, G.cowa, G. pedunculata and G.Lancifolia are the most important species in northeast India. ${ }^{3}$ Many species of Garcinia have edible arils and are consumed locally. ${ }^{4}$

The current study was undertaken to determine the bioactive compounds present as well as the antibacterial activity of methanol and ethanol extracts of $G$. pedunculata pericarp in vitro.

The antibacterial activities of methanol and ethanol extract of $G$. pedunculata pericarp were tested against the most common causative agent for UTI (Urinary Tract Infection) viz. uropathogenic E.coli (UPEC), K. pneumoniae, S.aureus, E. faecalis, P. aeruginosa and E. cloacae, and then compare the results obtained with that of the effect of the standard antibiotics.

\section{MATERIALS AND METHODS \\ Collection and identification of plant}

The plant sample (Fig. 1) was collected from its natural habitat and identified at Botanical Survey of India, Eastern Regional Centre, Shillong. G. pedunculata voucher specimen (Accession No. 96682) has been deposited at Assam Herbarium, BSI, Shillong, India.

Preparation of plant extract

The clean dried pericarp of $G$. pedunculata were grounded by motor-driven grinder into powder form. Ten (10) gms of powdered plant material was weigh and extracted in methanol and ethanol solvent in Soxhlet Hot Extraction Apparatus. The crude extract was subjected to filtration using Whatmann filter paper no. 1. The collected solution was dried in a rotary shaker (150 $\mathrm{rpm} ; 50^{\circ} \mathrm{C}$ ) and stored at $4^{\circ} \mathrm{C}$ until further use.

The reconstituted working methanol (MEGP) and ethanol (EEGP) extracts were prepared by dissolving the required amount of dry extract in their respective solvents and are employed directly without any adjustment of $\mathrm{pH}$.

\section{Preparation of standardized inoculum}

Each of the bacterial isolates were grown on Mueller-Hinton Agar (MHA, HiMedia) plate for $18-24 \mathrm{hrs}$. at $37 \pm 2^{\circ} \mathrm{C}$. Well-isolated colonies were inoculated into sterile Mueller-Hinton Broth (MHB, HiMedia) and the turbidity was adjusted against the $0.5 \mathrm{McFarland}$ standard to yield approximately $1.5 \times 10^{8} \mathrm{CFU} / \mathrm{ml}$.

Antibacterial Susceptibility Test (AST) of UTI clinical bacterial isolates against standard antibiotics by Disc Diffusion Method

The susceptibility of the clinical bacterial isolates to twelve (12) commonly employed different antibiotics viz. Ceftazidime CAZ 30mcg/ disc, Gentamicin GEN $10 \mathrm{mcg} /$ disc, Piperacillin PI $100 \mathrm{mcg} / \mathrm{disc}$, Amikacin AK $30 \mathrm{mcg} / \mathrm{disc}$, Cefepime CPM $30 \mathrm{mcg} / \mathrm{disc}$, Aztreonam AT $30 \mathrm{mcg} / \mathrm{disc}$, Cefoperazone CPZ $75 \mathrm{mcg} /$ disc, Ciproflaxacin CIP $5 \mathrm{mcg} / \mathrm{disc}$, Levoflaxacin LE $5 \mathrm{mcg} / \mathrm{disc}$, Imipenem IPM $10 \mathrm{mcg} / \mathrm{disc}$, Meropenem MRP $10 \mathrm{mcg} / \mathrm{disc}$ and Piperacillin/Tazobactam PIT 100/10mcg/ disc was assessed by disc diffusion method using HiMedia's Dodeca Disc for easy and relevant comparison and to ascertain the effectiveness of the extract of $G$. pedunculata.

Antibacterial activity of methanol and ethanol extracts of $G$. pedunculata towards UTI clinical bacterial isolates by Disc Diffusion Method

Antibacterial activity of methanol and ethanol extract of $G$. pedunculata towards different clinical isolates were assessed in terms of diameter of inhibition zone using disc diffusion method as stated by Kirby - Bauer et.al ${ }^{5}$ It is the recommended method of European Committee on Antimicrobial Susceptibility Testing (EUCAST) and National Committee for Clinical Laboratory Standard ( NCCLS ), USA . 
The isolates to be tested were, firstly, inoculated/spread on the surface of MHA using sterile spreader. Sterile 10-mm diameter blank discs (HiMedia) impregnated with $250 \mu \mathrm{l}$ of different plant extracts stock solution $(200 \mathrm{mg} /$ $\mathrm{ml}$ ) were place on the inoculated MHA plate as test disc. Blank disc impregnated with $250 \mu \mathrm{l}$ methanol and ethanol were used as negative control for methanol and ethanol plant extract respectively. Place the discs in an empty sterile petri dish and then apply the solution to the discs in an installment of $50 \mu \mathrm{l}, 100 \mu \mathrm{l}$ and $100 \mu \mathrm{l}$. Allow 15-30 minutes for the discs to absorb and dry at $40^{\circ} \mathrm{C}$ in an Oven before applying every installment. Disc of ampicillin (10 mcg) and methicillin (5mcg) antibiotics (HiMedia) were used as reference antibiotics. All test plates were incubated at $37 \pm$ $2^{\circ} \mathrm{C}$ for 18 to 24 hours and diameter of zones of inhibition produced by the plant extracts were measured. The experiment was repeated three times for each combination of extract and microbe. Antibacterial activity of methanol and ethanol extracts of G.pedunculata towards UTI clinical bacterial isolates by Well Diffusion Method

The susceptibility of different bacterial clinical isolates to the methanol and ethanol extract of $G$. pedunculata was determined in terms of diameter of zone of inhibition using agar well diffusion assay. Firstly, the MHA plates were spread with the inoculum and wells $(8 \mathrm{~mm}$ diameter) were cut out using a sterilized stainless steel well borer. The wells were then filled with 250 $\mu \mathrm{l}$ of the plant extracts $(200 \mathrm{mg} / \mathrm{ml})$. Wells filled with $250 \mu \mathrm{l}$ methanol and ethanol were used as negative control for methanol and ethanol plant extract respectively. Disc of ampicillin (10 mcg) and methicillin (5 mcg) antibiotics (HiMedia) were used as reference antibiotics. The bacteriainoculated plates were incubated at $37 \pm 2^{\circ} \mathrm{C}$ for 18 to 24 hours, and the diameter of any resulting zone of inhibition was measured. The experiment was repeated three times for each combination of extract and bacterial strain.

\section{MIC Determination by Broth Microdilution} Method supplemented with Resazurin

The MIC of the methanol extract (MEGP) was determined by using broth microdilution method, as described previously by Wiegand et al $^{6}$ supplemented with Resazurin dye. ${ }^{7}$ MHB was used as the diluent in a two-fold serial dilution of plant extract. Negative control (inoculum and MHB only) was also maintained. Solvent blanks and positive controls were also included.

The bacterial inoculum was prepared in the same manner as described above for the disc-diffusion method. Fifty (50) $\mu$ l of the adjusted inoculum were mixed into each Eppendorf tube containing $200 \mu \mathrm{l}$ of $\mathrm{MHB}$ and $250 \mu \mathrm{l}$ of each plant extract dilution in the dilution series. In an ambient air incubator, the capped microdilution vials were incubated at $37 \pm 2^{\circ} \mathrm{C}$ for 18 to 24 hours.

After incubation for 18 to $24 \mathrm{~h}$ at $37 \pm 2^{\circ} \mathrm{C}$, resazurin $(0.015 \%)$ was added to all the Eppendorf tubes (150 $\mu$ l per vial), and further incubated for 2-4 $\mathrm{h}$ for the observation of color change. On completion of the incubation, the Eppendorf tubes with the lowest concentration of the extract that shows no color change (blue resazurin color remained unchanged) is scored as the MIC value. The experiment was repeated three times.

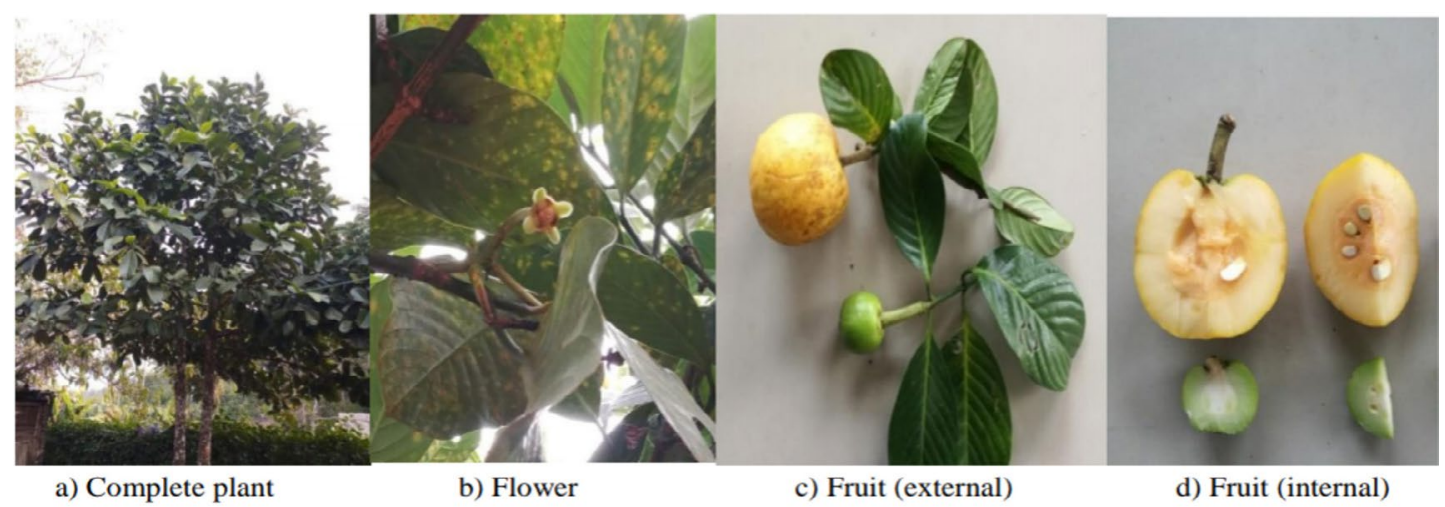

Fig. 1. Garcinia pedunculata 


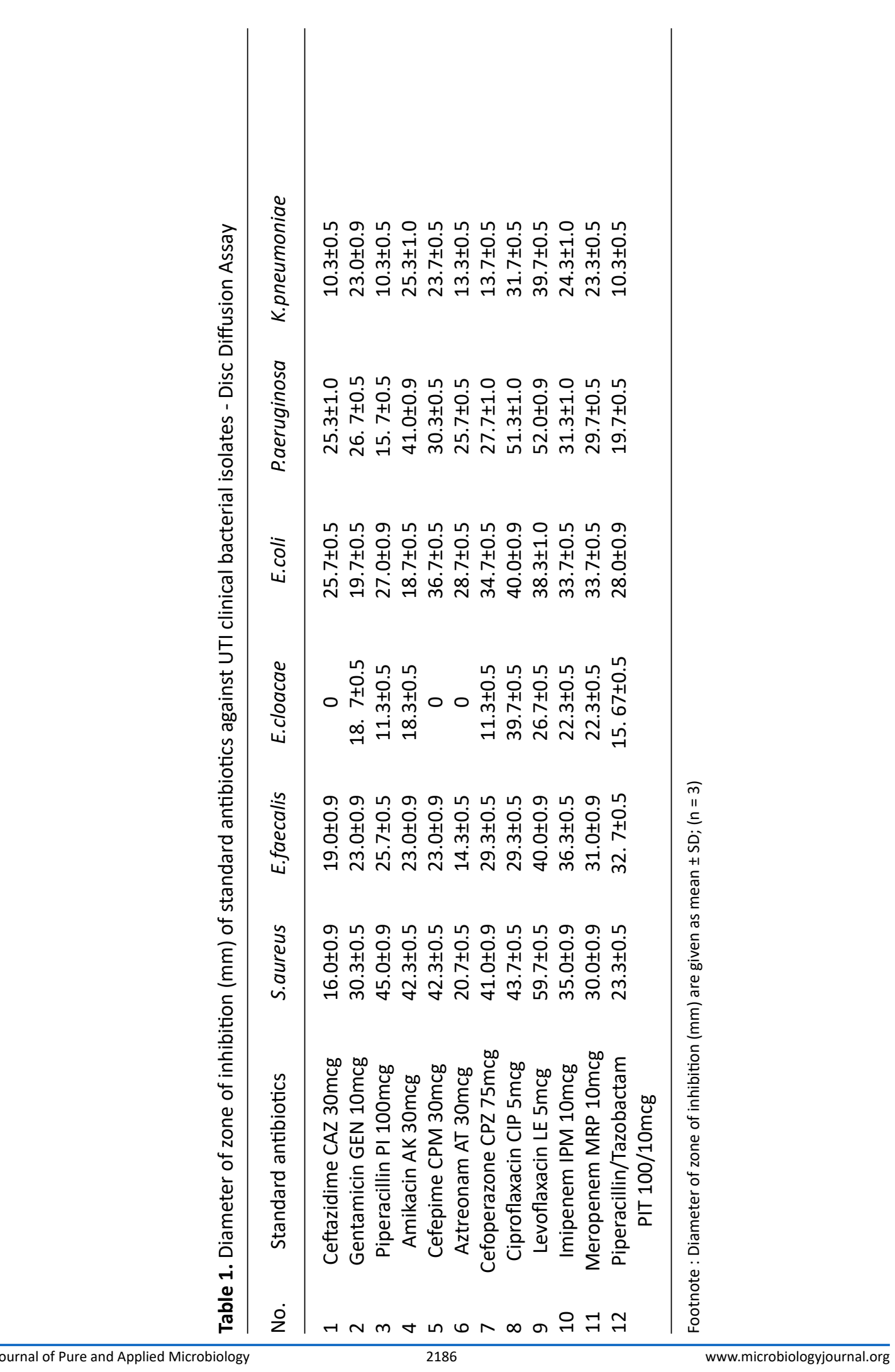


Table 2. Antibacterial activity of G.pedunculata extracts and some of the standard antibiotics against UTI bacterial isolates

\begin{tabular}{lcccccc}
\hline \multicolumn{7}{c}{ BacteriaDiameter of zone of inhibition $(\mathrm{mm})$ are given as } \\
mean \pm SD; $(\mathrm{n}=3)$
\end{tabular}

Footnote : MEGPDD = Methanol Extract of G. pedunculata (Disc Diffusion); EEGPDD = Ethanol Extract of G. pedunculata (Disc Diffusion); MEGPWD = Methanol Extract of G. pedunculata (Well Diffusion); EEGPWD = Methanol Extract of G. pedunculata (Well Diffusion); AMP = Ampicillin $10 \mathrm{mcg} ;$ MET = Methicillin $5 \mathrm{mcg}$.

\section{Minimum Bactericidal Concentration (MBC)}

The MBC was determined by directly plating the contents of the Eppendorf tube at a concentration higher than the MIC value. The lowest concentration of extract that did not allow any growth was taken to MBC.

\section{LC-MS Instrumentation and Experiment}

The methanol extract of $G$. pedunculata (MEGP) was subjected to LCMS analysis. The LC/ MS was performed on Waters ACQUITY UPLC-TQD Mass spectrometer model ACQ-TQD\#QBB1152 with Waters 2424 ELSD detector. The HPLC Column HYDROSPHERE C18, 12nm, $5 \mu \mathrm{m}, 250 \times 4.6 \mathrm{~mm}$, maintained at temperature of $35^{\circ} \mathrm{C}$ was used for separation. The solvents used were of LC-MS grade. The sample injection volume was $20.0 \mu \mathrm{l}$. A continuous gradient system was followed using mobile phase composed of acetonitrile (ACN) and formic acid (0.1\% FA, v/v in water) for 40 mins. At a flow rate of $1.5 \mathrm{~mL} / \mathrm{min}$, the extract was investigated using the following eluent mixtures:
1. $0-10$ min 5:95 $\rightarrow 30: 70(A C N: F A, v / v)$
2. $10-16 \min 30: 70 \rightarrow 60: 40$ (ACN : FA, v/v)
3. $16-24 \min 60: 40---80: 20$ (ACN : FA, v/v)
4. 24-35 min 80:20---5:95 (ACN: FA, v/v)
5. $25-40$ min $5: 95 \rightarrow 5: 95$ (ACN : FA, v/v)

The capillary temperature was $350^{\circ} \mathrm{C}$ and the ESI voltage was $2.5 \mathrm{kV}$. The detection was carried out in negative ion mode over a mass range of $150.0-750.0 \mathrm{~m} / \mathrm{z}$.

\section{RESULT}

Antibacterial Susceptibility Test of UTI clinical bacterial isolates against standard antibiotics by Disc Diffusion Method

The result of the antibacterial susceptibility test is given in Table 1 . The different cultures of the clinical bacterial isolates responded to standard antibiotics in a variable manner resulting in various size of zones of inhibition. The size of zone of inhibition range from $10.3 \pm 0.5$ (Piperacillin/Tazobactam PIT 100/10mcg against K.pneumoniae) to $59.7 \pm 0.5$ (Levoflaxacin LE $5 \mathrm{mcg}$ against S.aureus).

According to the $31^{\text {st }}$ edition of CLSI performance standard for antimicrobial susceptibility testing, E.coli was susceptible to all the 12 standard antibiotics tested; E.cloacae was resistant to CAZ, PI, CPM, AT, CPZ and PIT but susceptible to GEN, AK, CIP and LE; K.pneumoniae was susceptible to GEN, AK, CIP, LE, IPM and MRP but resistant to CAZ, PI, CPM, AT, CPZ and PIT; P.aeruginosa was susceptible to CAZ, GEN, AK, CPM, AT, CIP, LE and IPM : S. aureus was susceptible to GEN, CIP and LE: E.faecalis was susceptible to CIP and LE.

Antibacterial activity of methanol and ethanol extracts of $G$. pedunculata against UTI clinical bacterial isolates - Disc Diffusion Assay

To evaluate the antibacterial activity of $G$. pedunculata fruit extracts, two different solvents were used to determine which of them 
might offer optimal activities against UTI clinical bacterial isolates. The disc diffusion method was used to determine the presence of antibacterial activities. All the methanol and ethanol negative control discs did not produce any zone of inhibition against any of the tested clinical isolates.

Table - 2 and Fig. - $2 \& 3$ shows the diameter of the zones of inhibition produced by the methanol and ethanol extracts (Disc diffusion method) on the various test bacteria. The data presented in this paper pertains to extracts of crushed plant parts without any $\mathrm{pH}$ adjustment. Both the extracts produced very significant antibacterial activities against all the bacterial strains tested. The ethanol extract demonstrated zones of inhibition ranging from $10 \mathrm{~mm}$ (E.coli) to $16 \mathrm{~mm}$ (E.faecalis). The methanol extract showed zones of inhibition ranging from $10.7 \mathrm{~mm}(E$. cloacae, K.pneumoniae) to $19 \mathrm{~mm}$ (E. faecalis).The results were compared with those of ampicillin and methicillin as standard antibiotics. Both the solvent extracts $(200 \mathrm{mg} / \mathrm{ml})$ of $G$. pedunculata were not as potent as ampicillin (10 mcg) but are quite effective as methicillin $(5 \mathrm{mcg})$ antibiotics or even better.

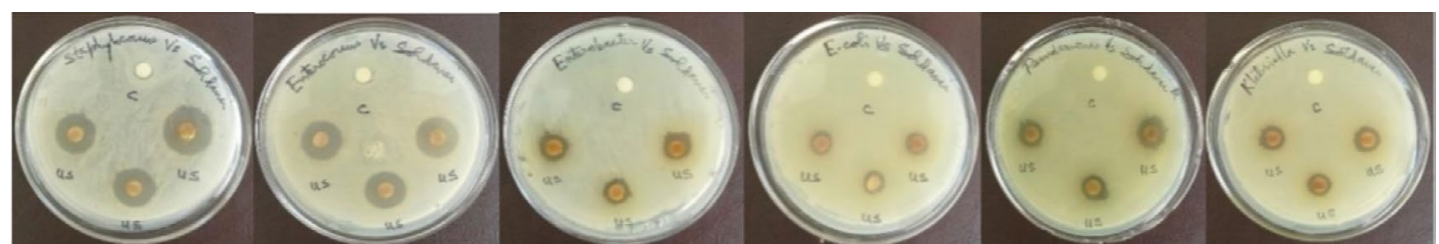

Fig. 2. Plates of Disc diffusion assay showing antibacterial activity of $G$. pedunculata ethanol extract on UTI clinical bacterial isolates. ( $C=$ Control disc impregnated with ethanol; US=Disc impregnated with EEGP).

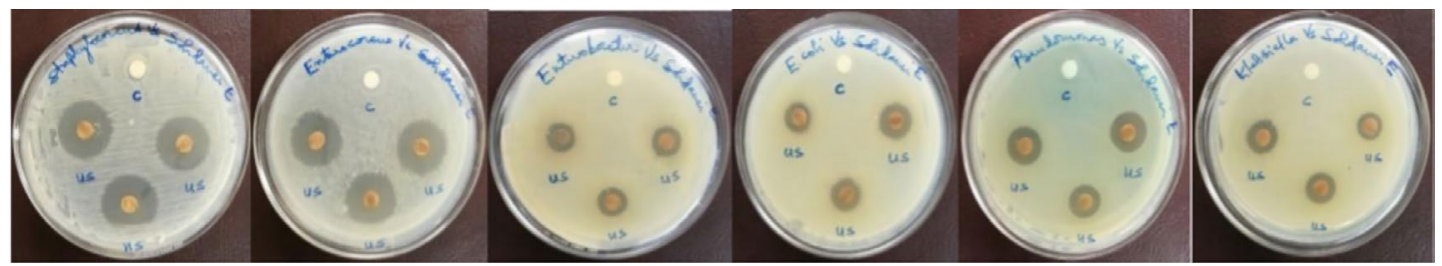

Fig. 3. Plates of Disc diffusion assay showing antibacterial activity of $G$. pedunculata methanol extract on UTI clinical bacterial isolates. ( $C=$ control disc impregnated with methanol; US=disc impregnated with MEGP).

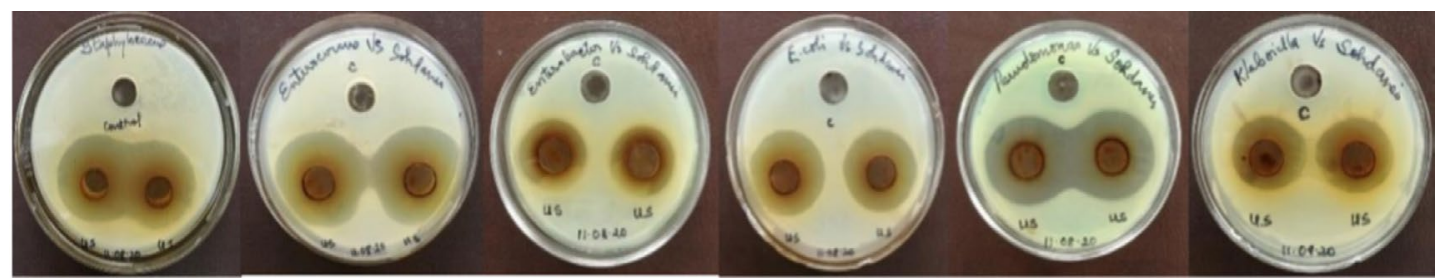

Fig. 4. Plates of Well diffusion assay showing antibacterial activity of $G$. pedunculata methanol extract on UTI clinical bacterial isolates. $(C=$ control well filled with methanol; US=well filled with MEGP).

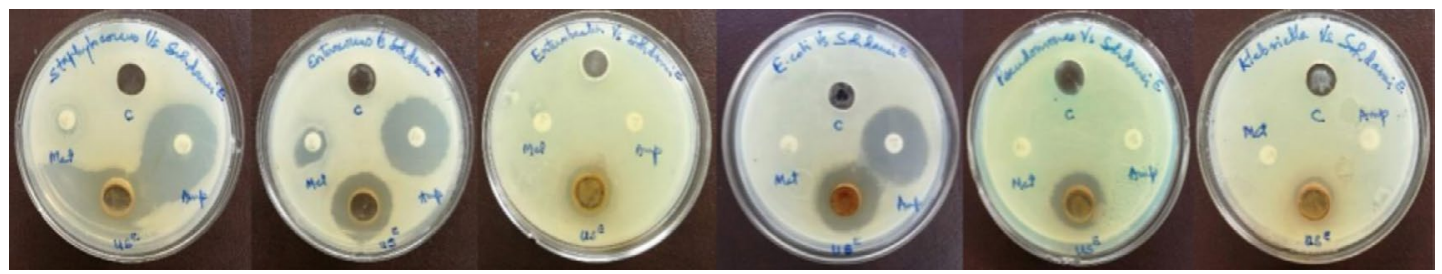

Fig. 5. Plates of Well diffusion assay showing antibacterial activity of $G$. pedunculata ethanol extract on UTI clinical bacterial isolates. ( $C=$ control well filled with ethanol; US=well filled with EEGP; $M$ et = methicillin disc; $A m p=a m p i c i l l i n$ disc). 


\section{Well Diffusion Assay}

In order to counter check and corroborate the result of the disc diffusion assay, the antibacterial activity of the methanol extract and ethanol extract of $G$. pedunculata was also determined by the well diffusion method. It was observe that both the organic solvent extracts of $G$. pedunculata were inhibitory to all the six bacterial isolates and the diameter of the zones of inhibition were relatively greater than the corresponding zones of inhibition observed in disc diffusion assay. Though the same volume of the extract were used against the six bacteria, the bigger zone of inhibition is expected in the well diffusion assay as the size of the wells ( $8 \mathrm{~mm}$ ) are comparatively greater than the size of the disc $(6 \mathrm{~mm})$. All the methanol and ethanol negative control discs did not produce any zone of inhibition against any of the tested clinical isolates (Table - 2, Fig. - 4 \& 5)

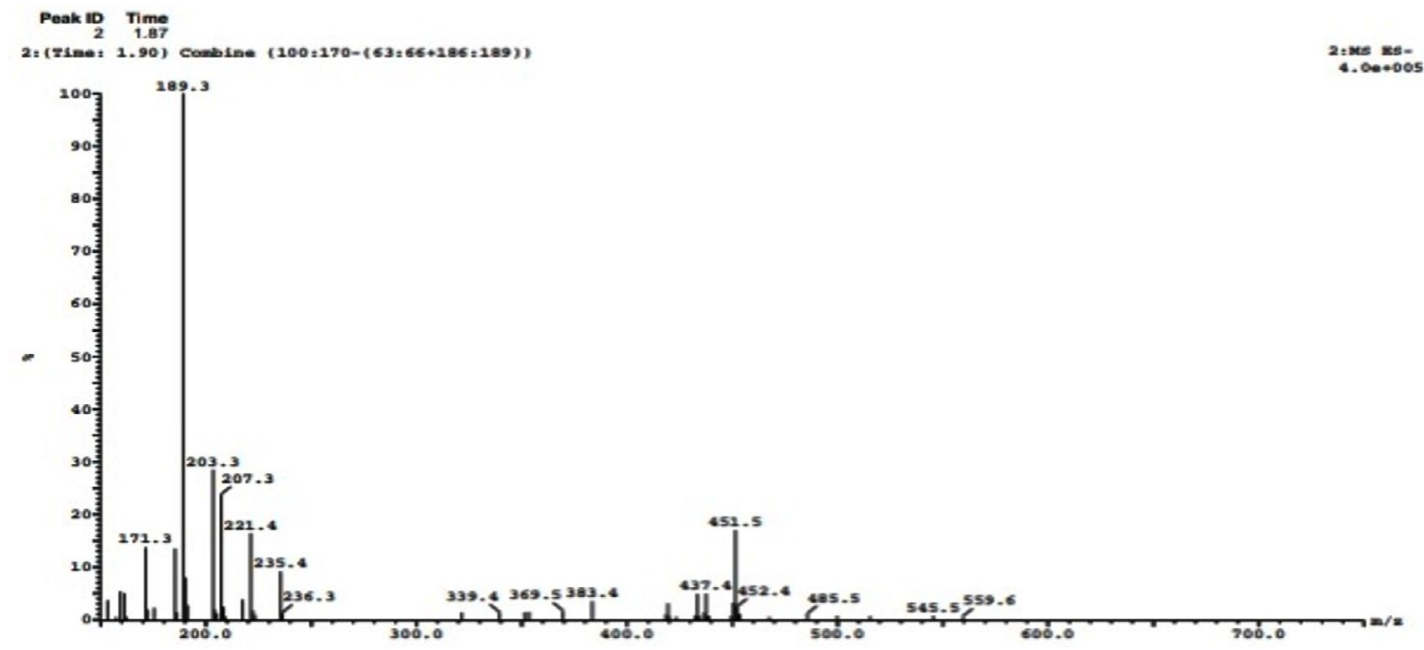

Fig. 6 (i). Mass spectrum at the retention time 1.87 .

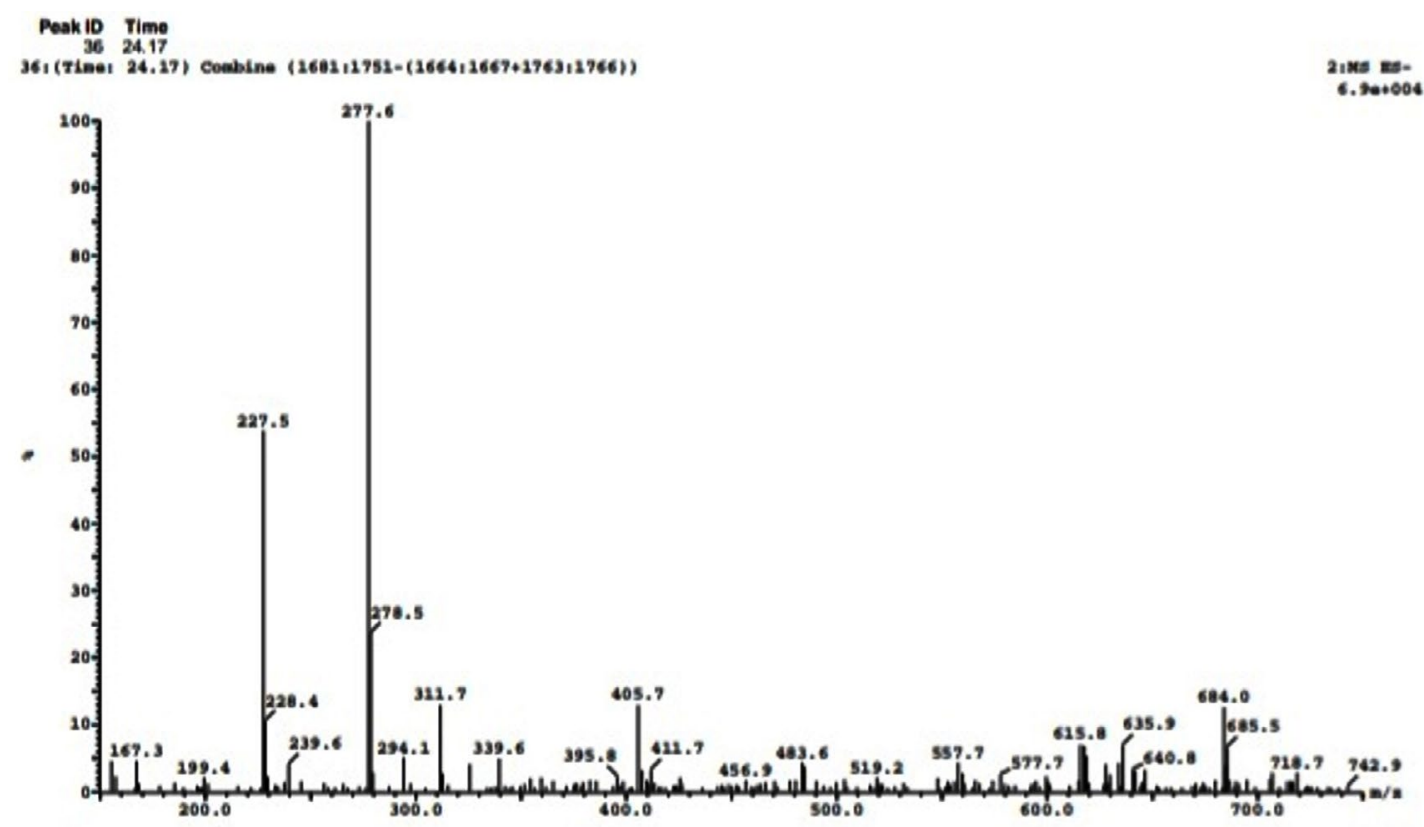

Fig. 6 (ii). Mass spectrum at the retention time 24.17. 
Minimum Inhibitory Concentration (MIC) of $\mathbf{G}$. pedunculata

MIC is used to determine the potency of the antimicrobial compounds towards the susceptible bacteria. An antimicrobial agent with lower MIC value is considered better as less compound is required to inhibit growth of the bacteria. The MEGP showed antibacterial activities against both GPB and GNB. The inhibitory effect of the extract increased with increasing concentration $(1.56-100 \mathrm{mg} / \mathrm{ml})$. The MEGP is approximately equally potent against S.aureus, E.faecalis and P.aeruginosa, with MIC being $12.5 \mathrm{mg} / \mathrm{ml}$. Against E.cloacae, E.coli and K.pneumoniae, the MIC of the

Peak 10 Time

46: (7ine, 26.58) Coebine (1852,1922-(1824,1827+1942,1945))

$2, x \in=0$

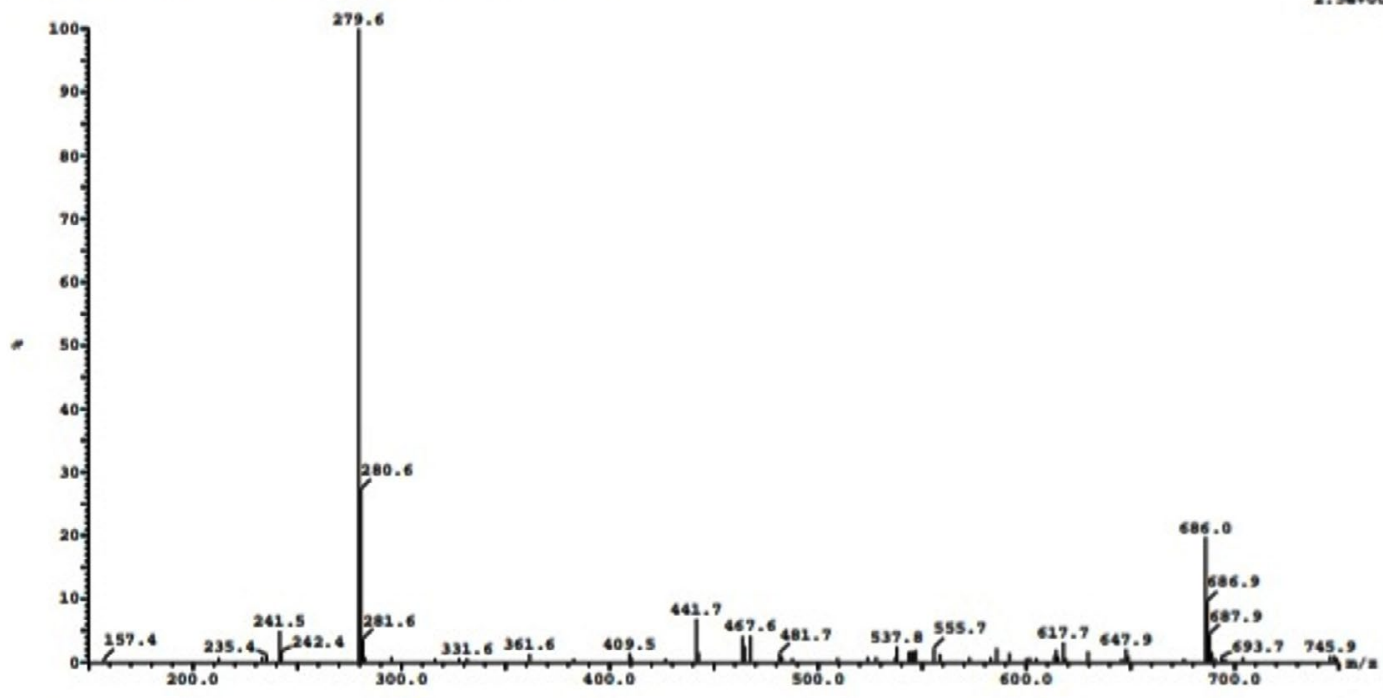

Fig. 6 (iii). Mass spectrum at the retention time 26.55 .

\section{Peak ID Time}

69: (Time: 30.48) Combine $(2129: 2199-(2112: 2115+2211: 2214))$

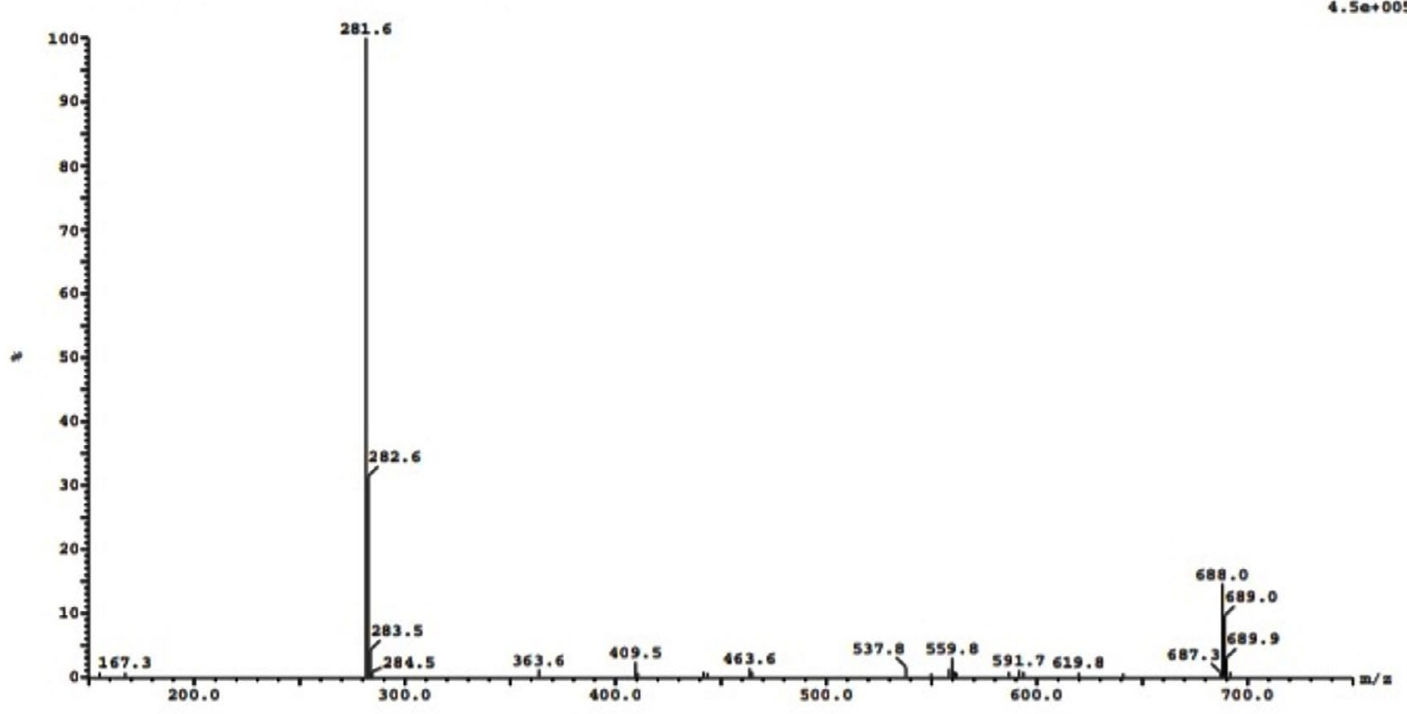

Fig. 6 (iv). Mass spectrum at the retention time 30.48 . 


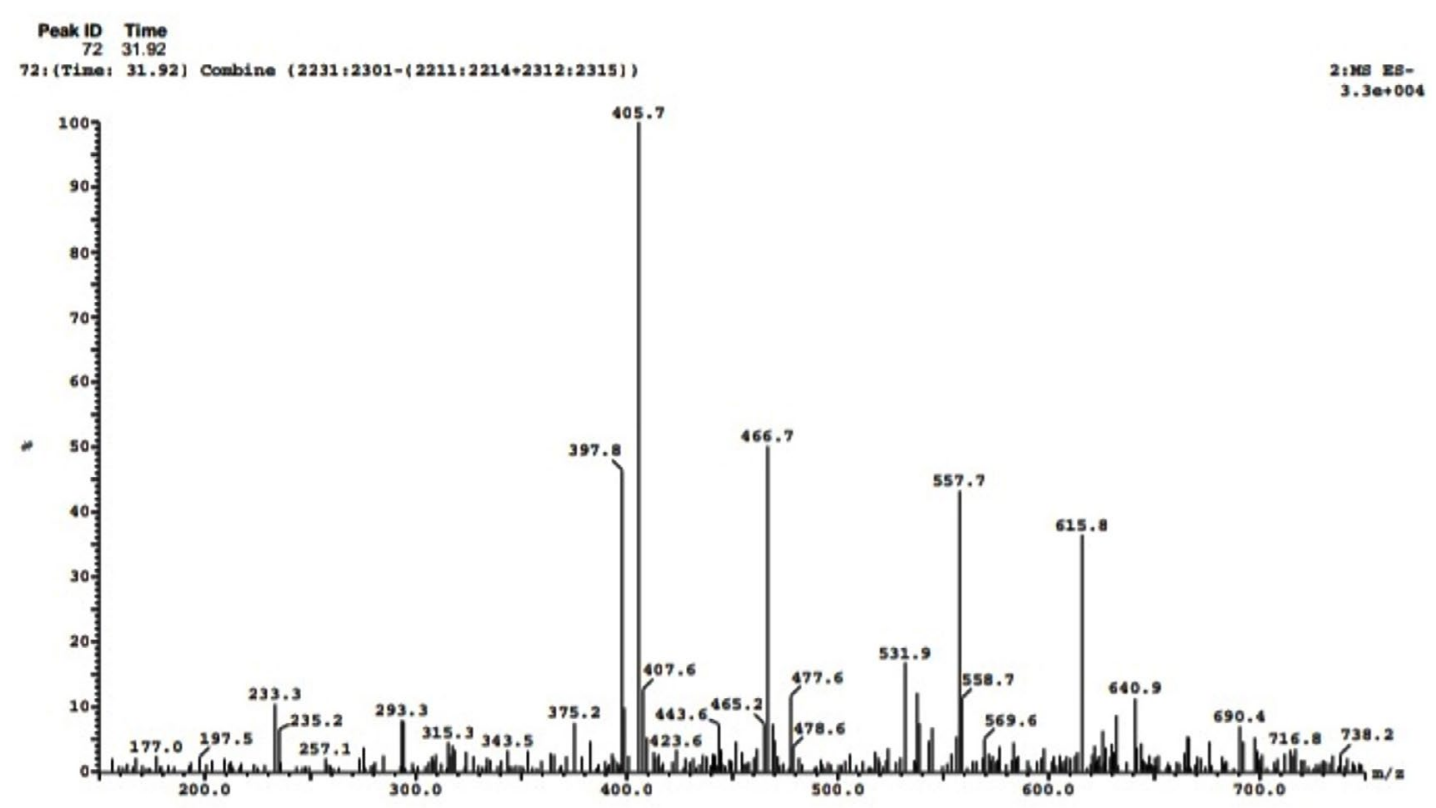

Fig. 6 (v). Mass spectrum at the retention time 31.92.

MEGP was observed to be approximately $25 \mathrm{mg} /$ $\mathrm{ml}$. This result also suggest that the MIC of the MEGP is bacterial genus/species dependent.

Minimum Bactericidal Concentration (MBC) of G. pedunculata

MEGP showed antibacterial activity against all the tested Gram-negative bacteria as well as Gram-positive bacteria. The MBC values was found to be approximately $25 \mathrm{mg} / \mathrm{ml}$ against S.aureus, E.faecalis and P.aeruginosa while $50 \mathrm{mg} /$ $\mathrm{ml}$ was the observed $\mathrm{MBC}$ against $E$. cloacae, E.coli and K.pneumoniae.

\section{LC-MS Result}

The methanol extract of $G$. pedunculata (MEGP) was selected for LCMS analysis over ethanol extract (EEGP) since it was observed that it gives larger zone of inhibition against the bacteria tested. It implies that methanol may be a better organic solvent for extraction of antibacterial compounds from $G$. pedunculata fruit. LC-MS of the methanol extract of $G$. pedunculata fruit revealed presence of several compounds. Five of these compounds were identified as Hydroxy Citric Acid Lactone (MW-190), Garcinone E (MW464), $\alpha$-Mangostin (MW-410), $\beta$-Mangostin (MW424), and $\gamma$-Mangostin (MW-396). Identification were carried out based on molecular weight, using the mass spectra of the LC-MS. Retention times, UV and mass spectral data of compounds were compared to literature data and to those of authentic standards, where available, for unambiguous identification. The mass spectra of Hydroxy Citric Acid Lactone, Garcinone E, $\alpha$-Mangostin, $\beta$-Mangostin, and $\gamma$-Mangostin are shown in Fig. 6 (i-v).

Hence, LC-MS analysis confirmed that Hydroxy Citric Acid Lactone (MW-190), Garcinone E (MW-464), $\alpha$-Mangostin (MW-410), $\beta$-Mangostin (MW-424), and $\gamma$-Mangostin (MW-396) are an important phytochemical content of the methanol extract of $G$. pedunculata fruit. Garcinone $E$, $\alpha$-Mangostin, $\beta$-Mangostin and $\gamma$-Mangostin are important phytochemical compound belonging to the group of xanthones, which are well known for their antibacterial, antifungal, antiviral, antioxidant, anti-inflammatory and antitumor activities. All these phytochemical compounds have been reported from several Garcinia species including G.indica, G.cambogia, G.atrovirdis and G. cowa and G.travancorica. ${ }^{8-10}$

\section{DISCUSSION}

The antimicrobial activity of different species of Garcinia had been investigated by 


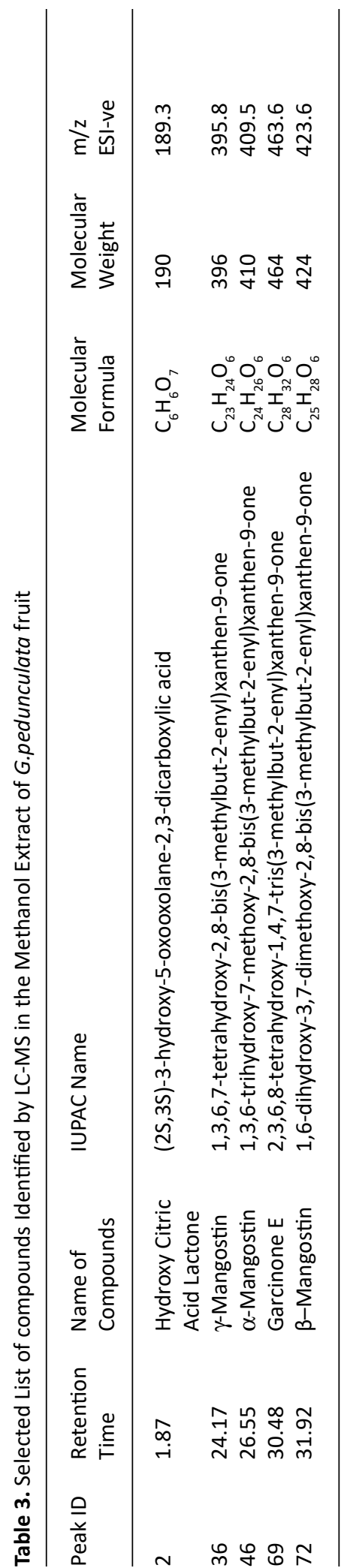

various researchers with an encouraging result till date. Negi et al ${ }^{11}$ reported that certain foodborne pathogens and spoilage bacteria, including B.cereus, B.coagulans, B.subtilis, S.aureus, and E.coli, are sensitive to crude hexane and chloroform extracts of Garcinia cowa and Garcinia pedunculata fruit rinds. ${ }^{11}$ Torrungruang et a $\mathrm{a}^{12}$ also observed that G.mangostana Pericarp extract exert antibacterial activity against cariogenic Streptococcus mutans. ${ }^{12}$

Priya et al $^{13}$ study revealed the antibacterial activity of Pericarp extract of G.mangostana against Staphylococcus aureus, Staphylococcus albus and Micrococcus luteus. ${ }^{13}$ Mangosteen pericarp extract has long been known for its broad-spectrum antibacterial activity against a number of GPB and GNB, particularly those linked to skin infections, diarrhoea, TB, and acne. $\alpha$-mangostin, one of the xanthone derivatives derived from mangosteen extract, has been shown to have the strongest antibacterial action. ${ }^{14-19}$

The present investigation revealed the potency of both methanol and ethanol extracts of $G$. pedunculata as an antibacterial agent. $G$. pedunculata is effective as an inhibitory agent against both GPB as well as GNB. The antibacterial activity can be attributed to its phytochemical constituents. ${ }^{20}$ The antibacterial activity may be due to an individual compound or synergistic effect of more than one compound present in the medicinal plant extract. Heymsfield et $\mathrm{al}^{8}$, Kumar et $\mathrm{al}^{9}$ and Aravinda et al ${ }^{10}$ reported xanthones, biflavonoids, benzophenones, benzoquinones, and triterpenes are bioactive chemicals found in Garcinia species that exhibit antibacterial, antifungal, antioxidant, and cytotoxic properties. ${ }^{8-10}$

The antibacterial activity of MEGP was quantitatively evaluated by determining its minimum inhibitory concentration (MIC) values and minimum bactericidal concentration (MBC). As the bigger zone of inhibition was observed with methanol extract of $G$. pedunculata (MEGP) than that of ethanol extract of $G$. pedunculata (EEGP), MEGP was preferred to EEGP for determination of MIC and MBC. The MEGP is considered to be bactericidal rather than bacteriostatic since its $\mathrm{MBC} / \mathrm{MIC}$ ratio is $\leq 4$. An antimicrobial agent is considered bactericidal if the $\mathrm{MBC}$ is not more than fourfold higher than the MIC. ${ }^{21}$ 


\section{CONCLUSION}

Our research concluded that $G$. pedunculata exhibited broad-spectrum antibacterial activity. Further investigation leading to the isolation of pure compounds and antibacterial assay is highly recommended. Nevertheless, G. pedunculata have been in use for many years as ethnomedicinal plants to treat various ailments. This paper establishes a scientific foundation for the use of $G$. pedunculata in the treatment of UTI infections. Further research could lead to their adoption as safe antibacterial alternatives to synthetic medications.

\section{ACKNOWLEDGMENTS}

Authors wished to acknowledge Council of Scientific and Industrial Research - Central Drug Research Institute, India and Botanical survey of India, Shillong, Meghalaya for the HPLC-ESI-MS work and identification of the plant material, respectively. Our gratitude also goes to Department of Microbiology, Woodland Hospital, Shillong for the supply of clinical bacterial isolates.

\section{CONFLICT OF INTEREST}

The authors declare that there is no conflict of interest.

\section{AUTHORS' CONTRIBUTION}

Both the authors listed have made a substantial, direct and intellectual contribution to the work, and approved it for publication.

\section{FUNDING}

None.

\section{DATA AVAILABILITY}

The datasets generated and/or analysed during the current study are available from the corresponding author on reasonable request.

\section{ETHICS STATEMENT}

This article does not contain any studies with human participants or animals performed by any of the authors.

\section{REFERENCES}

1. Mawlong W. The miraculous and magnificient power of a local medicinal herb: U Sohdanei. 2014:1-9. (Ed. Ribanskhemlang Mawlong)
2. Roberts E. Vegetable Materia Medica of India and Ceylon. Bishen Singh Mahendra Pal Singh, Dehra Dun, India. 1984.

3. Parthasarathy U, Babu KN, Kumar RS, Ashis GR, Mohan S, Parthasarathy VA. Diversity of Indian Garcinia - a Medicinally Important Spice Crop in India. Acta Horticulturae. 2013;979:467-476. doi: 10.17660/ ActaHortic.2013.979.50

4. CSIR. The Wealth of India - Raw Materials. Vol. IV. New Delhi, India. 1956.

5. Bauer AW, Kirby WMM, Sherris JC, Turck M. Antibiotic susceptibility testing by a standardized single disk method. Am J Clin Pathol. 1966;45(4):493-496. doi: 10.1093/ajcp/45.4_ts.493

6. Wiegand I, Hilpert K, Hancock REW. Agar and broth dilution methods to determine the minimal inhibitory concentration (MIC) of antimicrobial substances. Nature Protocols. 2008;3(2):163-175. doi: 10.1038/ nprot.2007.521

7. Elshikh M, Ahmed S, Funston S, et al. Resazurinbased 96-well plate microdilution method for the determination of minimum inhibitory concentration of biosurfactants. Biotechnol Lett. 2016;38(6):1015-1019. doi: 10.1007/s10529-016-2079-2

8. Heymsfield SB, Allison DB, Vasselli JR, Pietrobelli A, Greenfield D, Nunez C. Garcinia cambogia (hydroxycitric acid) as a potential antiobesity agent: A randomized controlled trial. The Journal of the American Medical Association. 1998;280(18):15961600. doi: 10.1001/jama.280.18.1596

9. Kumar S, Sharma S, Chattopadhyay SK. Rapid and sensitive HPLC-PDA method for simultaneous identification and quantification of dietary weight reducing compound hydroxy citric acid lactone and chemo preventive compounds isoxanthochymol and xanthochymol in Garcinia indica. Int Food Res J. 2013;20:397-402.

10. Aravinda APA, Pandey R, Kumar B, Asha KRT, Rameshkumar KB. Phytochemical Screening of Garcinia travancorica by HPLC-ESI-QTOF Mass Spectrometry and Cytotoxicity Studies of the major Biflavonoid Fukugiside. Natural Product Communications. 2016;11(12):1839-1842. doi: 10.1177/1934578X1601101216

11. Negi PS, Jayaprakasha GK, Jena BS. Antibacterial activity of the extracts from the fruit rinds of Garcinica cowa and Garcinia pedunculata against food borne pathogens and spoilage bacteria. Food Science and Technology. 2008;41(10):1857-1861. doi: 10.1016/j. Iwt.2008.02.009

12. Torrungruang $\mathrm{K}$, Vichienroj $\mathrm{P}$, Chutimaworapan $\mathrm{S}$. Antibacterial activity of mangosteen pericarp extract against cariogenic Streptococcus mutans. CU Dent J. 2007;30:1-10.

13. Priya V, Jainu M, Mohan SK, Saraswathi, Gopan CS. Antimicrobial activity of pericarp extract of Garcinia mangostana Linn. International Journal of Pharma Sciences and Research. 2010;1(8):278-281

14. linuma $\mathrm{M}$, Tosa $\mathrm{H}$, Tanaka $\mathrm{T}$, et al. Antibacterial activity of xanthones from guttiferaeous plants against methicillin-resistant Staphylococcus aureus. J Pharm Pharmacol. 1996;48(8):861-865. doi: 10.1111/j.2042- 
7158.1996.tb03988.x

15. Sundaram BM, Gopalakrishnan C, Subramanian S, Shankaranarayanan D, Kameswaran L. Antimicrobial activities of Garcinia mangostana. Planta Med. 1983;48(5):59-60. doi: 10.1055/s-2007-969882

16. Mahabusarakum W, Phongpaichit S, Jansakul C, Wiriyachitra P. Screening of antibacterial activity of chemicals from Garcinia mangostana. Songklanakarin J Sci Technol. 1983;5:337-340.

17. Mahabusarakam W, Wiriyachitra P, Phongpaichit S. Antimicrobial activities of chemical constituents from Garcinia mangostana Linn. J Sci Soc Thailand. 1986;12:239-242. doi: 10.2306/ scienceasia1513-1874.12.23910

18. Sakagami Y, linuma M, Piyasena KGNP, Dharmaratne HR. Antibacterial activity of alpha-mangostin against vancomycin resistant Enterococci (VRE) and synergism with antibiotics. Phytomedicine. 2005;12(3):203-208. doi: 10.1016/j.phymed.2003.09.012

19. Suksamrarn S, Suwannapoch N, Phakhodee W, et al. Antimycobacterial activity of prenylated xanthones from the fruits of Garcinia mangostana. Chem Pharm Bull (Tokyo). 2003;51(7):857-859. doi: 10.1248/ cpb.51.857

20. Ushimaru PI, da Silva MTN, Di Stasi LC, Barbosa L, Fernandes Jr. A. Antibacterial activity of medicinal plant extracts. Braz J Microbiol. 2007;38(4):717-719. doi: 10.1590/S1517-83822007000400024

21. Levison ME. Pharmacodynamics of antimicrobial drugs. Infect Dis Clin N Am. 2004;18(3):451-465. doi: 10.1016/j.idc.2004.04.012 